\title{
Gender differences among Indigenous Canadians experiencing homelessness and mental illness
}

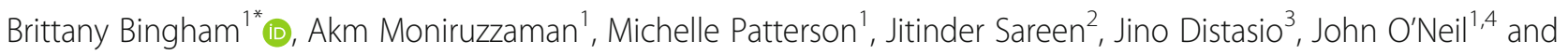
Julian M. Somers ${ }^{1}$

\begin{abstract}
Background: Indigenous people are over represented among homeless populations worldwide and the prevalence of Indigenous homelessness appears to be increasing in Canadian cities. Violence against Indigenous women in Canada has been widely publicized but has not informed the planning of housing interventions. Despite historical policies leading to disenfranchisement of Indigenous rights in gender-specific ways, little is known about contemporary differences in need between homeless Indigenous men and women. This study investigated mental health, substance use and service use among Indigenous people who met criteria for homelessness and mental illness, and hypothesized that, compared to men, women would have significantly higher rates of trauma, suicidality, substance dependence, and experiences of violence.
\end{abstract}

Methods: This study was conducted using baseline (pre-randomization) data from a multi-site trial. Inclusion in the current analyses was restricted to participants who self-reported Indigenous ethnicity, and combined eligible participants from Vancouver, BC and Winnipeg, MB. Logistic regression analyses were used to model the independent associations between gender and outcome variables.

Results: In multivariable regression models among Indigenous participants $(n=439)$, female gender was predictive of meeting criteria for PTSD, multiple mental disorders, current high suicidality and current substance dependence. Female gender was also significantly associated with reported physical (AOR: 1.52, 95\% Cl=1.10-2.23) and sexual (AOR: 6.31, 95\% $\mathrm{Cl}=2.78-14.31$ ) violence.

Conclusions: Our analyses of Indigenous men and women who are homeless illustrate the distinct legacy of colonization on the experiences of Indigenous women. Our findings are consistent with the widely documented violence against Indigenous women in Canada. Housing policies and services are urgently needed that take Indigenous historical contexts, trauma and gender into account.

Trial registration: This trial has been registered with the International Standard Randomized Control Trial Number Register and assigned ISRCTN42520374; ISRCTN57595077; ISRCTN66721740.

Keywords: Canada, Homelessness, Indigenous, Mental health, Substance use, Service use, Women, Gender differences

\footnotetext{
* Correspondence: bld@sfu.ca

'Somers Research Group, Faculty of Health Sciences, Simon Fraser University,

Burnaby, BC, Canada

Full list of author information is available at the end of the article
}

(c) The Author(s). 2019 Open Access This article is distributed under the terms of the Creative Commons Attribution 4.0 International License (http://creativecommons.org/licenses/by/4.0/), which permits unrestricted use, distribution, and reproduction in any medium, provided you give appropriate credit to the original author(s) and the source, provide a link to the Creative Commons license, and indicate if changes were made. The Creative Commons Public Domain Dedication waiver (http://creativecommons.org/publicdomain/zero/1.0/) applies to the data made available in this article, unless otherwise stated. 


\section{Background}

Indigenous $^{1}$ peoples are overrepresented among homeless populations worldwide and urban Indigenous homelessness is on the rise [1-4]. In Canada, Indigenous people are five times more prevalent among the homeless compared with the general population [1, 3]. Indigenous people account for $2.5 \%$ of Canada's population but comprise $38 \%$ of the homeless in Vancouver, BC [5]. Recent estimates indicate that over $30 \%$ of the Canadian shelter population is Indigenous, a crisis that is rooted in historical determinants and systemic discrimination [3]. Longstanding structural inequities associated with colonization (e.g., the Indian Act, residential schools, marginalization and systemic racism, and dispossession of lands) are commonly noted as contributors to Indigenous homelessness $[1-3,6]$. However, The effects of colonial policies, including disconnection from community, culture, and lands are experienced differently by Indigenous men and women, and these gendered perspectives have received little attention from researchers $[2,6]$.

Historically, Indigenous women played central and powerful roles in their communities as matriarchs and the custodians of cultural and tribal traditions [7]. Indigenous women have been subjected to coercive racialized policies intended to subjugate their traditional matriarchal roles and authority [8]. In 1850, The Canadian government introduced a definition of "Indigenous", whereby women forfeited their Indigenous status when they married a non-Indigenous man, while Indigenous men retained their status regardless of spousal ethnicity [8]. Furthermore, Indigenous women were legally denied the right to any marital property upon divorce or separation with men retaining the right to the family home [9]. The right to property defined under the Indian Act, has had far reaching implications in the lives, mobility and safety of Indigenous women. A patriarchal social structure was imposed by European settlers, and over time the belief that women were inferior to men began to influence Indigenous communities as increasing numbers of Indigenous women were disenfranchised and compelled to raise their families without customary connections to tradition, culture or community. A gendered hierarchy was also integral to the operation of Indian residential schools and continues to influence the marginalization of Indigenous women [10]. Indigenous gendered health disparities must be framed by discussions of the distinct historical experiences of Indigenous men and women and the contemporary impact these

\footnotetext{
${ }^{1}$ The term 'Indigenous' will be used throughout this paper to collectively describe the Indigenous peoples of Canada, inclusive of those who identify as 'Aboriginal', or First Nations, Métis and Inuit. This term is used while also acknowledging the diversity of cultures, languages and traditions that exist among Indigenous Canadians.
}

factors have on Indigenous marginalization, street involvement, trauma and homelessness.

Menzies (2009) qualitatively examined the experiences of homeless Indigenous men and found that family disconnection, intergenerational trauma and violence were subjectively the key influences on their life trajectories [11]. Despite the shared historical traumas of Indigenous men and women, Indigenous women in Canada bear a disproportionate burden of disease, poverty, homelessness, violence and incarceration [12]. Violence toward Indigenous women in Canada has been identified as a national human rights crisis $[13,14]$. There have been more than 160 cases of missing or murdered Indigenous women and girls in the province of British Columbia and 79 cases in Manitoba, most of which are unsolved $[13,15,16]$. Indigenous Canadians' rates of violent victimization are more than double those of the non-Indigenous population and rates of sexual assault are nearly 3 times higher than for non-Indigenous Canadians [17]. Violence shapes the context within which Indigenous women access (or avoid) housing and health services, and contributes to their "invisibility" [18, 19]. Indigenous scholars have called for research examining how colonialism, racism and sexism determine health and healthcare access among Indigenous women [7, 12, 20]. Little is known about homelessness among Indigenous women and their experiences of violence, trauma, and coercion, which may shape their interactions with service providers.

Beyond ethnicity, additional barriers are experienced by women who are mothers struggling to maintain housing for their families [21]. Thurston, Turner and Bird (2016) discuss the role of domestic and interpersonal violence (IPV) as a key contributor to homelessness among Indigenous women, and the racialized barriers Indigenous women face when seeking support for IPV, including the absence of culturally appropriate supports for women and their children [6]. In addition, being female and Indigenous carries an increased risk of trauma (e.g., PTSD), often as a consequence of violent assault [14]. Recent research has discussed the crucial importance of expanding culturally relevant and safe services for Indigenous peoples' as a whole [12]. However, few studies have investigated the relevance of cultural and gender-based differences within marginalized Indigenous groups [22].

Indigenous women are overrepresented among homeless women [3, 23-25], and are more likely than men to provide care for children or other family members while experiencing core housing need [3, 26]. No known research to date has quantified the impact that homelessness among Indigenous women has on the ability of their children and future generations to thrive. In 2016, $60 \%$ of children and youth in 
care in $\mathrm{BC}$ were Indigenous and this percentage has been increasing over time with Indigenous children 15 times more likely to be in care than non-Indigenous children [27]. Intergenerational trauma is a direct result of colonial child welfare policies from the 1960 's at the height of the residential school era, when provinces removed Indigenous children and placed them in foster care, most often with non-Indigenous families [27]. Indigenous women are five times more likely than non-Indigenous women to be single parents [7]. Research on marginalized women engaged in sex work in Vancouver found that over one-third had their children forcibly removed and that Indigenous women had a $66 \%$ greater odds of child apprehension compared to non-Indigenous women [28]. Some authors contend that continued apprehension of Indigenous children into government care is contemporary cultural genocide, evidenced by the fact that the number of children in care today exceeds the number at the height of residential schools [27, 29]. Little is known about the impact of historical and current child apprehensions on homeless Indigenous women's levels of trauma and trust for government programs and services.

Several studies indicate that pathways to homelessness differ based on gender [30, 31]. For example, homeless women are more likely to be victims of violence compared to men and more likely to report family disruption or dysfunction while men are more likely to report loss of a job, mental illness, and substance use problems as precursors to homelessness [32]. Clark and Rich (2003) highlighted that homeless populations are diverse in ethnicity, gender and pathways to homeless and recommended matching housing interventions to the characteristics of the service users [33]. However, few studies have focused on the distinct needs of Indigenous women who are homeless, contributing to their invisibility' in the public policy realm [34].

Our study aimed to address this gap by investigating the relevance of gender in a large sample of Indigenous people who experienced homelessness and mental illness in two Canadian cities (Vancouver, British Columbia; Winnipeg, Manitoba). Our study focus was within Indigenous peoples, and not a comparison between people of differing ethnicities. We hypothesized, based on the forgoing historical and contemporary rationale, that compared to Indigenous men, Indigenous women would have significantly higher prevalence of current trauma, suicidality, substance dependence, and recent experiences involving violence and threats.

\section{Methods}

This study is part of a 4-year research demonstration project, the At Home Study, which investigated the effectiveness of Housing First ${ }^{2}$ in five Canadian cities, with each site contributing a different emphasis specific to the local context. The Winnipeg site addressed the needs of Indigenous people, while Vancouver addressed addiction $[35,36]$. The current study drew from baseline data from both Vancouver and Winnipeg due to the over-representation of Indigenous people among those who are homeless in both cities [35-37].

\section{Ethics statement and community engagement}

Our multi-site randomized trial included people who met criteria for homelessness and mental illness. Community engagement processes were specific to each site. In Vancouver focus groups and advertised open meetings were conducted with people who had been or were homeless, convened in custody and community settings, and at an Indigenous support centre [36, 37]. Indigenous people and other community stakeholders were engaged in the development and implementation of this research. Investigators engaged organizations providing services to Indigenous people who were homeless or precariously housed. People with Indigenous ancestry were members of the investigative team in roles as field researchers, research coordinator, and co-investigators [37]. Winnipeg convened a Cultural Lens Committee comprised of elders and traditional teachers to provide guidance to the project. Indigenous teachings and practices were integrated into the interventions delivered in Winnipeg, and a Lived Experience Circle was created to ensure that Indigenous experiences were honoured and promoted through the research. Throughout the Winnipeg site, participants and persons with lived experience (PWLE) were involved extensively with multiple roles on the project such as representatives on an advisory committee, employed as research staff and assigned key roles working with service providers [37]. PWLE assisted in facilitating integrated knowledge exchange working with staff of the interventions and directly to bring participant perspectives into the research and interventions [38]. Details of the study protocols are published elsewhere $[35,36]$. The parent trials are registered as follows: ISRCTN42520374; ISRCTN57595077; ISRCTN66721740. All variables were collected pre-randomization. Ethical review and approval was conducted by the Research Ethics Boards at Simon Fraser University, The University of British Columbia and the University of Manitoba with endorsement from the University of Winnipeg.

\footnotetext{
${ }^{2}$ Housing First (HF) originated from the Pathways model in New York City and involves building a portfolio of rental accommodations scattered in different neighbourhoods providing clients with meaningful choices in the location and setting of their residence. Clients are supported in their homes with Assertive Community Treatment or Intensive case management depending on their needs. HF has been shown to promote residential stability and community integration [35].
} 


\section{Study sites}

Vancouver has a large visible population of homeless and mentally ill individuals located within a central downtown neighborhood which is characterized by high crime rates and an open drug market [35]. The Downtown Eastside of Vancouver (DTES) includes a high number of single room occupancy (SRO) hotels which comprise the least expensive housing in the area and have been characterized as bed bug infested places of criminal predation [39-41]. SRO's have become the only housing option for many low income individuals who depend on government assistance [39]. The greater Vancouver region is home to 11 First Nations communities neighboring or within the urban center [42]. British Columbia is home to 203 distinct First Nations province-wide, many of which come to the city center of Vancouver to receive health services. Métis Nation BC represents 38 distinct Métis communities and there are nearly 90,000 self-identified and 18,000 provincially registered Métis people in BC [43]. Vancouver is a city characterized by extremely high property prices and lack of affordable housing as well as the 'deinstitutionalization' of those with mental illness to community setting with insufficient supports [35].

The city of Winnipeg was selected as a site for the At Home/Chez Soi study due to an overrepresentation of Indigenous people in the city who were homeless and living with mental illness. Winnipeg is a prairie city with a population of approximately 730,000 and home to the country's largest urban Indigenous population with over 72,000 identifying in the last census [38]. The growing urban Indigenous population is younger than the general population, with Indigenous children representing closer to $30 \%$ of the total Indigenous population in Winnipeg [38]. It has been estimated that more than $80 \%$ of Winnipeg's homeless have originated from Indigenous communities. Winnipeg has had a vacancy rate below $2 \%$ since 2001and long waitlists persist for those seeking affordable shelter. Similar to Vancouver, rental housing supply in Winnipeg is located mostly in the inner city where often housing is older or in need of repair [38].

\section{Participants}

Participants were recruited through referral from over 40 agencies in Vancouver, and 50 agencies in Winnipeg, including: homeless shelters, drop-in centers, homeless outreach-teams, hospitals, community mental health teams, and criminal justice programs. Eligibility criteria included: being a legal adult (19 years or older), current mental disorder, and being absolutely or precariously housed $[35,44]$. Absolute homelessness was defined as living in a shelter or on the streets for a minimum of two weeks in the past year [36]. Precarious housing was defined as living in a rooming house, hotel or transitional housing, individuals must also have experienced at least two episodes of absolute homelessness in the past year with one episode lasting for at least 4 weeks. [35, 36, 45]. For inclusion, participants must have experienced two or more episodes of absolute homelessness in the past year or one episode lasting at least one month in the past year [35].

\section{Data collection}

An initial face-to-face interview was conducted to screen for eligibility. Trained research staff conducted interviews and obtained written informed consent from all participants $[36,46]$. Enrolled participants provided socio-demographic information and details concerning homelessness, mental illness, substance use, physical health, service use, and quality of life [36]. The following standard questionnaires were administered: Health service access [36]; Community integration scale; Health related quality of life (EuroQol 5D) [47-49]; Global Appraisal of Individual Needs (GAIN-SPS), Substance Problem Scale [50]; SF-12 Health Survey [51]; Quality of Life Index, 20-item [52]; Mini International Neuropsychiatric Interview (MINI) [53]; Social support items and food security; Health, social, and justice use inventory [36]; and Multnomah Community Ability Scale (MCAS) [54]; Recovery Assessment Scale, 22-item [47, 48] and Adverse Childhood Experiences Questionnaire [36]. Detailed descriptions of the instruments included in the questionnaire are described in previous protocol papers [36]. Participants received a cash honorarium of $\$ 30$ upon completion of the baseline interview and $\$ 20$ for each subsequent interview.

\section{Variables}

Independent variables included gender, ethnicity, and level of need. Gender was categorized based on the question, "What is your gender? Do you identify as: male, female, transgender, transsexual, other, declined." Indigenous ethnicity was self-reported and did not include participants who indicated they were part-Indigenous or who self-identified as "Mixed/Other". Participants who self-identified as Indigenous and were asked to specify: Inuit, First Nations Status, Indigenous from outside Canada, Métis, First Nations Non-Status, and other. Participants' level of need was categorized "high needs" (HN), based on the MCAS score of 62 or lower or current bipolar or psychotic disorder; as well as one of the following: legal involvement in the past year, substance dependence in the past month, and two or more hospitalizations for mental illness in the past 5 years. All other eligible participants were categorized as "moderate needs" (MN) [35].

Dependent variables included posttraumatic stress disorder (PTSD), multiple mental disorders, suicidality, substance and alcohol dependence and experiences of violence. 
Participants' mental illness was categorized as severe or less severe. The severe cluster of mental disorders includes at least one of current (i.e. past month) psychotic disorder, mood disorder with psychotic features, and hypomanic or manic episode, as identified through the MINI. The less severe cluster includes at least one of current major depressive episode, panic disorder and posttraumatic stress disorder (PTSD) [35]. Substance dependence was also identified using the MINI and GAINSPS. Frequency of use included all illicit drugs (i.e. not alcohol). Infectious disease was based on a positive selfreport diagnosis of HIV, Hepatitis B, or Hepatitis C [35]. Experiences of violence in the past 6 months were identified by asking participants "During the past 6 months, did anyone take or try to take something from you by force or threat of force?". Participants were also asked "During the past 6 months, did anyone threaten to hit or attack you, or threaten you with a weapon?" and "During the past 6 months, has anyone forced you or attempted to force you into any unwanted sexual activity, by threatening you, holding you down or hurting you in some way?" Participants who answered 'yes' were considered to have experienced violent victimization in this analysis.

Self-reported involvement with health services was collected for the past 6 months and included visiting a family doctor, psychiatrist, Emergency Room (ER), and transport by ambulance. Access to health care was categorized based on the questions, "Is there a place that you usually go to when you're sick or in need of advice about your health?" and "In the past 6 months, was there ever a time when you needed health care but you did not receive it?" Criminal justice services included contact with the police that did not result in arrest and contact that resulted in arrest or being held in a police cell for less than $24 \mathrm{~h}$.

\section{Statistical analysis}

Pearson Chi-square tests or Fisher's exact test were used to conduct comparisons of categorical variables between groups (Vancouver vs. Winnipeg participants; Indigenous vs. non-Indigenous participants and Indigenous female vs. Indigenous male participants). Comparisons of numeric variables (e.g., age at enrolment) between groups were conducted using the Student $\mathrm{t}$ - test and Wilcoxon's rank-sum test as appropriate. Comparisons were conducted across socio-demographic variables, homelessness variables, mental disorder, substance use, health conditions, trauma, violence and service use. Univariate and multivariable logistic regression analyses were used to model the independent associations between gender and a series of a priori outcome variables. Outcome variables that were significant at the $p<0.05$ level in univariate analysis were considered for inclusion in the multivariable logistic regression analyses. Each multivariable model included gender (primary independent variable) and the following controlling variables: age (continuous); gender (male, female); ethnicity (Aboriginal, White, other); need level (high, moderate); marital status (single, other); site (Vancouver, Winnipeg); education (completed high school, incomplete high school); have children (under age 18). Given the exploratory nature of our study we did not control for multiple comparison $[55,56]$. Both unadjusted and adjusted odds ratios and 95\% Confidence intervals (CI) are reported. SPSS Version 21 was used to conduct these analyses. Institutional review and ethics approval was provided by Simon Fraser University's office of Research Ethics application number 2009 s0231.

\section{Results}

\section{Sample characteristics}

In Vancouver, 497 participants met eligibility criteria and $77(16 \%)$ identified as Indigenous. Of the 513 eligible participants in Winnipeg, 362 (71\%) identified as Indigenous. Selected baseline characteristics for the full sample $(n=1010)$ are summarized here and additional details have been published elsewhere [37]. Differences in the proportions of Indigenous and non-Indigenous people in each site were associated with further differences involving need level, gender, ethnicity, education, hospitalizations, arrests, housing status, mental illness severity, and suicidality $(p \leq 0.05)$. In both Vancouver and Winnipeg, most participants were male: 359 (73\%) and $326(64 \%)$ respectively. Five participants self-identified as transgender and 2 participants identified as transsexual. Although the small number of transgender and transsexual does not enable separate analyses, it is worth noting that 5 of the 7 people who identified as transgender or transsexual also identified as Indigenous.

In total, 439 people (44\%) from the combined sample identified as Indigenous. Most Indigenous participants were male (61\%); categorized as moderate needs (59\%); had not completed high school (75\%); and reported a lifetime duration of homelessness greater than 3 years (52\%). Compared to non-Indigenous participants, Indigenous participants were more likely to have children under the age of 18-years; report hospitalization for mental illness; and report lifetime durations of homelessness longer than three years.

Compared to Indigenous men, women were significantly more likely to be younger $(p=0.002)$; single $(p=0.03)$; and have minor-aged children $(p<0.001$; see Table 1$)$. Indigenous women were also more likely than Indigenous men to meet criteria for high levels of suicidality $(p<.001)$; PTSD $(\mathrm{p}=0.002)$; less severe mental disorder $(p=0.034)$; and two or more mental disorders $(\mathrm{p}=0.002)$. Furthermore, Indigenous women were more likely than Indigenous men to report experiences of violence, 
including: forced or attempted unwanted sex $(\mathrm{p}<0.001)$; attempts to take something by force or threat $(p=0.048)$; threats to hit or attack them $(p=0.039)$.

Unadjusted (UOR) and adjusted odds ratios (AOR) and $95 \%$ confidence intervals included in the univariate and multivariable analyses are presented in Table 2. Results from multivariable logistic regression analyses confirm the findings of the bivariate comparisons and indicate that among the Indigenous participants, female gender was predictive of meeting criteria for PTSD (AOR: 1.81 ; 95\% $\mathrm{CI}=1.22-2.69$ ); multiple mental disorders (AOR: $1.86 ; 95 \% \mathrm{CI}=1.20-2.86$ ); current high suicidality (AOR: 3.97; 95\% CI $=1.88-8.4$ ); and current substance dependence (AOR: 1.91; 95\% CI $=1.26-2.91$ ). Female gender was also predictive of reports of violence such as, someone taking something from them by force or threat of force (AOR: 1.52, 95\% CI $=1.10-2.23$ ), someone threatening to hit or attack them or threatening them with a weapon in the past 6 months (AOR: 1.51, 95\% CI =1.00-2.27), and someone forcing or attempting to force sexual activity on them by threatening or holding them down or hurting them (AOR: 6.31, $95 \% \mathrm{CI}=2.78-14.31$ ).

\section{Discussion}

The results of this study are consistent with the hypothesis that Indigenous women who become homeless are markedly afflicted by violent victimization, post-traumatic stress and suicidality. Indigenous women were 6 times more likely than Indigenous men to be victims of forced sexual violence, and were significantly more likely to exhibit symptoms of PTSD and suicidality. Our findings support the interpretation that Indigenous women continue to experience forms of violence, social exclusion, and marginalization. Women comprised a substantially higher percentage of our Indigenous sample (39\%) compared to our non-Indigenous sample (26\%). These findings can be meaningfully interpreted as a reflection of colonizing practices that sought to extinguish Indigenous women's historic roles as matriarchs and custodians of cultural continuity. However, our research design does not address the causal role of these historical factors.

Our results highlight the importance of recognizing the distinct experiences of Indigenous women when providing housing and relevant support services, particularly those emphasizing culturally and trauma informed care. Consistent with other research $[2,17]$, our study found that Indigenous women experience violence at alarming rates. A 2009 Statistics Canada study reported that rates of violent victimization for Indigenous women (63\% of females between the ages of 15 to 34) were three times higher than for non-Indigenous women [57, 58]. Homelessness literature has discussed differential impacts of sexual victimization among women compared to men in terms of increased psychopathology and legal involvement [32, 59]. Halseth discusses violence as a serious threat to the wellbeing of Indigenous women, perpetuating a gender specific form of marginalization established under colonization [7]. Support services for Indigenous women survivors of violence urgently need to be strengthened to reverse these historically rooted forces.

Indigenous women in this study were almost 2 times more likely than Indigenous men to be diagnosed with post-traumatic stress disorder (PTSD). PTSD is closely linked to historical and current experiences of violence experienced by Indigenous peoples. Research has documented that women are more likely to develop PTSD than men [60], and high rates of PTSD have been described among residential school survivors; however with known low rates of service engagement in Indigenous communities these may be underestimates [14].

Indigenous women in this study were close to 4 times more likely than Indigenous men to have high suicide risk or suicidality. Almost every Indigenous woman in this analysis actively thought about death and suicide with high suicidality among $95 \%$ of respondents. This shocking statistic is consistent with the sparse research that exists documenting the suicide crisis among Indigenous Canadians, particularly that Indigenous women are more likely to commit suicide than other Canadian women [7]. Suicide among Indigenous people is an issue of global concern and continues to devastate communities across Canada [61, 62]. Global evidence has shown that experiences of intimate partner violence among women are significantly associated with poor health, suicidal thoughts, prior attempts, and poor mental health [63]. Eynan and colleagues (2002) studied 330 homeless adults and found a high prevalence of suicidal ideation (61\%). Furthermore, in their study $78 \%$ of female participants compared to $56 \%$ of male participants reported suicidal ideation, and $57 \%$ of the women had attempted suicide compared to $28 \%$ of the men [64, 65].

Substantial research has shown that suicide rates among Indigenous communities in Canada are of epidemic proportions. Despite significant investments, research investigating the determinants of suicidality within the Indigenous population and identifying promising interventions remains preliminary [66]. Indigenous scholars have raised concerns about using a homogenous approach to suicide interventions highlighting the diversity within the Indigenous population and variation in suicide rates. Research that examines intersectional meanings of identity, environment, Indigenous culture and community in relation to suicide is required [67]. Some scholars have recommended addressing Indigenous suicidality through the implementation of culturally relevant programming, which incorporates Indigenous worldviews, culture, ceremony, 
Table 1 Socio-demographic, mental health, substance use and service use characteristics for Vancouver and Winnipeg Indigenous Female and Male Home Study Participants $(N=439)$

\begin{tabular}{|c|c|c|c|}
\hline Variable & $\begin{array}{l}\text { Indigenous Female } \\
(N=169,38.9 \%) \\
N(\%)\end{array}$ & $\begin{array}{l}\text { Indigenous Male } \\
(N=265,61.1 \%) \\
N(\%)\end{array}$ & $P$ value \\
\hline \multicolumn{4}{|l|}{ Need Level } \\
\hline High Need & $74(43.8)$ & $104(39.2)$ & \multirow[t]{2}{*}{0.348} \\
\hline Moderate Need & $95(56.2)$ & $161(60.8)$ & \\
\hline \multicolumn{4}{|l|}{ Age at Enrollment } \\
\hline Youth & $25(14.8)$ & $28(10.6)$ & \multirow[t]{3}{*}{0.002} \\
\hline 25-44 Years & $100(59.2)$ & $161(60.8)$ & \\
\hline 44 Plus Years & $44(26.0)$ & $76(28.7)$ & \\
\hline \multicolumn{4}{|l|}{ Education } \\
\hline High School or Higher & $42(25.0)$ & $67(25.4)$ & \multirow[t]{2}{*}{0.008} \\
\hline Less than High School & $126(75.0)$ & $197(74.6)$ & \\
\hline \multicolumn{4}{|l|}{ Marital Status } \\
\hline Single (never married) & $117(69.2)$ & $191(72.6)$ & \multirow[t]{3}{*}{0.030} \\
\hline Married/Partner & $18(10.7)$ & $11(4.2)$ & \\
\hline Separated/Widow/divorced & $34(20.1)$ & $61(23.2)$ & \\
\hline Have Children (under 18) & $111(66.5)$ & $111(42.7)$ & $<0.001$ \\
\hline Hospitalized for mental illness over 6 months in past 5 years & $9(5.4)$ & $13(5.0)$ & 0.870 \\
\hline Hospitalized for mental illness over 2 times in the past 5 years & $44(26.7)$ & $62(23.6)$ & 0.471 \\
\hline Arrested/Imprisoned/Probation/Community sanction in past 6 months & $57(33.9)$ & $111(41.9)$ & 0.098 \\
\hline One or more nights in hospital, detox, shelter and jail in last 6 months & $155(91.7)$ & $226(85.3)$ & 0.046 \\
\hline \multicolumn{4}{|l|}{ Length of Homelessness Lifetime } \\
\hline $1-3$ years & $81(49.7)$ & $123(47.9)$ & \multirow[t]{2}{*}{0.714} \\
\hline 3 years plus & $82(50.3)$ & $134(52.1)$ & \\
\hline \multicolumn{4}{|l|}{ Length of homelessness lifetime } \\
\hline 12 months & $33(20.2)$ & $56(21.8)$ & \multirow[t]{3}{*}{0.833} \\
\hline $13-60$ months & $72(44.2)$ & $106(41.2)$ & \\
\hline 60 months plus & $58(35.6)$ & $95(37.0)$ & \\
\hline \multicolumn{4}{|l|}{ Length of homelessness longest single period } \\
\hline 12 months & $67(41.6)$ & $121(47.8)$ & \multirow[t]{3}{*}{0.216} \\
\hline 13-60 months & $69(42.9)$ & $95(37.5)$ & \\
\hline 60 months plus & $25(15.5)$ & $37(14.6)$ & \\
\hline \multicolumn{4}{|l|}{ Age first homeless } \\
\hline 18 years or less & $50(29.8)$ & $78(29.8)$ & \multirow[t]{4}{*}{0.643} \\
\hline 19-30 years & $54(32.1)$ & $86(32.8)$ & \\
\hline $31-40$ years & $30(17.9)$ & $56(21.4)$ & \\
\hline Over 40 years & $34(20.2)$ & $42(16.0)$ & \\
\hline \multicolumn{4}{|l|}{ Housing Status } \\
\hline Absolutely Homeless & $111(65.7)$ & $196(74.0)$ & \multirow[t]{2}{*}{0.064} \\
\hline Precariously Housed & $58(34.3)$ & $69(26.0)$ & \\
\hline \multicolumn{4}{|l|}{ Mental illness \& substance use } \\
\hline Less severe mental illness & $150(88.8)$ & $215(81.1)$ & 0.034 \\
\hline Multiple mental disorders $(\geq 2)$ & $126(74.6)$ & $160(60.4)$ & 0.002 \\
\hline Current PTSD & $98(58.0)$ & $114(43.0)$ & 0.002 \\
\hline
\end{tabular}


Table 1 Socio-demographic, mental health, substance use and service use characteristics for Vancouver and Winnipeg Indigenous Female and Male Home Study Participants ( $N=439)$ (Continued)

\begin{tabular}{|c|c|c|c|}
\hline Variable & $\begin{array}{l}\text { Indigenous Female } \\
(N=169,38.9 \%) \\
N(\%)\end{array}$ & $\begin{array}{l}\text { Indigenous Male } \\
(N=265,61.1 \%) \\
N(\%)\end{array}$ & $P$ value \\
\hline Current suicidality & $160(94.7)$ & $216(81.5)$ & $<0.001$ \\
\hline Current alcohol dependence & $111(65.7)$ & $176(66.4)$ & 0.875 \\
\hline Current substance dependence & $108(63.9)$ & $130(49.1)$ & 0.002 \\
\hline \multicolumn{4}{|l|}{ Age first alcohol use } \\
\hline$\geq 14 \mathrm{yrs}$ & $62(38.5)$ & $111(42.7)$ & \multirow[t]{2}{*}{0.397} \\
\hline$\leq 13 \mathrm{yrs}$ & $99(61.5)$ & $149(57.3)$ & \\
\hline \multicolumn{4}{|l|}{ Age first drug use } \\
\hline$\geq 14 \mathrm{yrs}$ & $73(45.9)$ & $124(49.4)$ & \multirow[t]{2}{*}{0.491} \\
\hline$\leq 13 \mathrm{yrs}$ & $86(54.1)$ & $127(50.6)$ & \\
\hline \multicolumn{4}{|l|}{ GAIN-SPS score of substance use } \\
\hline Less severe $(0-3)$ & $86(55.1)$ & $158(63.2)$ & \multirow[t]{2}{*}{0.106} \\
\hline Severe $[4,5]$ & $70(44.9)$ & $92(36.8)$ & \\
\hline \multicolumn{4}{|l|}{ Physical illness, service utilization and trauma } \\
\hline Blood borne diseases & $46(27.5)$ & $74(28.2)$ & 0.875 \\
\hline Two or more physical illness & $159(94.1)$ & $225(84.9)$ & 0.004 \\
\hline Have a regular medical doctor & $131(77.5)$ & $164(61.9)$ & 0.001 \\
\hline $\begin{array}{l}\text { Place you usually go when you are sick or need advice } \\
\text { about your health }\end{array}$ & $146(86.4)$ & $222(84.4)$ & 0.572 \\
\hline Needed health care, but did not receive it in past 6 months & $91(54.5)$ & $130(49.8)$ & 0.344 \\
\hline $\begin{array}{l}\text { During past } 6 \mathrm{~m} \text { did anyone take or try to take something from } \\
\text { you by force or threat of force? }\end{array}$ & $78(47.0)$ & $97(37.3)$ & 0.048 \\
\hline $\begin{array}{l}\text { During past } 6 \mathrm{~m} \text { did anyone threaten to hit or attack you, or threaten } \\
\text { you with a weapon? }\end{array}$ & $105(63.6)$ & $139(53.5)$ & 0.039 \\
\hline $\begin{array}{l}\text { During past } 6 \mathrm{~m} \text { has anyone forced you or attempted to force you } \\
\text { into any unwanted sexual } \\
\text { activity, by threatening you, holding you down or hurting you in some way? }\end{array}$ & $31(18.7)$ & $9(3.5)$ & $<0.001$ \\
\hline
\end{tabular}

PTSD: Post-Traumatic Stress Disorder

GAIN-SPS: Global Assessment of Individual Need -Substance Problem Scale

Data in bold are outcome variables that were significant at the $p<0.05$ level

elders and spirituality [68]. Chandler has asserted that Indigenous communities with low suicide rates are marked by multiple community factors including: higher levels of self-determination on the community level, selfgovernment, active attempts to restore traditional land title, preserve Indigenous language, culture and women's roles in governance [68]. Individualistic approaches to addressing Indigenous suicide have failed continually and with an absence of promising interventions, Indigenous suicide research must be reoriented to focus on critical community level factors that foster cultural resurgence, reclamation and self-determination $[67,68]$.

It has been argued that mainstream definitions of homelessness do not adequately describe the meaning of Indigenous homelessness. For example, Thistle (2017) described Indigenous homelessness as not simply the lack of a structure for habitation but a disconnection and isolation from kin relations and relationships to the land as understood through Indigenous worldviews. Thistle calls for acknowledgment that racism and discrimination are entrenched in Canadian society and prevent Indigenous people from thriving. $\mathrm{He}$ asserts that homelessness must be culturally understood and that Indigenous worldviews and experiences must inform solutions [69]. The current study indicates that gender should be added to the contextualization of Indigenous homelessness, and must inform the development of interventions and supports. With abundant evidence that the unravelling of Indigenous cultural systems perpetuates Indigenous homelessness, it is clear that decolonizing approaches are essential, particularly for Indigenous women $[1,2,61,69]$.

Indigenous scholars have called for the development of Indigenous gender-based analytic approaches that account for the experiences of all members of communities including girls, women, trans and two spirit peoples [10]. Several 
Table 2 Logistic Regression analysis to estimate the effect of gender on mental illness, substance use, trauma and violence among Vancouver and Winnipeg Indigenous 'At home' participants ( $\mathrm{N}=439)$

\begin{tabular}{|c|c|c|c|c|}
\hline Dependent variable & $\begin{array}{l}\text { Unadjusted OR } \\
(95 \% \mathrm{Cl})\end{array}$ & P Value & $\begin{array}{l}\text { Adjusted OR } \\
(95 \% \mathrm{Cl})\end{array}$ & $P$ Value \\
\hline Current PTSD & $1.83(1.24-2.70)$ & 0.002 & $1.81(1.22-2.69)$ & 0.003 \\
\hline Multiple mental disorders $(\geq 2)$ & $1.92(1.26-2.94)$ & 0.003 & $1.86(1.20-2.86)$ & 0.005 \\
\hline Current suicidality & $4.03(1.93-8.45)$ & $<0.001$ & $3.97(1.88-8.4)$ & $<0.001$ \\
\hline Current substance dependence & $1.84(1.24-2.73)$ & 0.003 & $1.91(1.26-2.91)$ & 0.002 \\
\hline $\begin{array}{l}\text { During past } 6 \mathrm{~m} \text { did anyone take or try to take something from you } \\
\text { by force or threat of force? }\end{array}$ & $1.49(1.00-2.21)$ & 0.048 & $1.52(1.10-2.23)$ & 0.042 \\
\hline $\begin{array}{l}\text { During past } 6 \mathrm{~m} \text { did anyone threaten to hit or attack you, or threaten } \\
\text { you with a weapon? }\end{array}$ & $1.52(1.02-2.27)$ & 0.039 & $1.51(1.00-2.27)$ & 0.046 \\
\hline $\begin{array}{l}\text { During past } 6 \mathrm{~m} \text { has anyone forced you or attempted to force you into } \\
\text { any unwanted sexual activity, by threatening you, holding you down or } \\
\text { hurting you in some way? }\end{array}$ & $6.35(2.94-13.74)$ & $<0.001$ & $6.31(2.78-14.31)$ & $<0.001$ \\
\hline
\end{tabular}

Controlled for age (continuous), need level (high, moderate), marital status (single, other), site (Vancouver, Winnipeg), education (high school or higher, less than high school), have children (under 18)

PTSD: Post-Traumatic Stress Disorder

Data in bold are outcome variables that were significant at the $p<0.05$ level

studies have shown that LGBTQ2S ${ }^{3}$ young people are overrepresented among youth experiencing homelessness [69-72]. Research on LGBTQ2S homelessness is scarce yet it is important to acknowledge that Indigenous gendered experiences of homelessness, violence and mental health are not simply limited to binary gender experiences. Hunt (2015), describes the erasure of two-spirit people as part of colonial violence resulting from racialized gender hierarchies that has led to current conceptions of gender as binary in health research [10]. Although the current study did not collect data on two-spirit and other experiences of gender, this gap in research is important to acknowledge in the framing of gendered health disparities among Indigenous Canadians, particularly because Indigenous LGBTQ2S individuals are at risk for both violence and homelessness and yet are largely unrepresented in discussions, analyses and recommendations.

\section{Study limitations}

Despite the strengths of our study design (e.g., large sample size, structured diagnostic interviews), several limitations should be considered. Our reliance on self-report may have introduced recall-bias and other sources of error. A study comparing self-report measures in the current study with corresponding administrative records

\footnotetext{
${ }^{3}$ LGBTQ2S is used to refer to those who identify as Lesbian, Gay, Bisexual, Trans, Queer and Two-Spirit. Two Spirit is a term used in some Indigenous communities, encompassing sexual, gender, cultural and spiritual identity. Two-Spirit is reflective of complex understandings of gender in Indigenous cultures. There is a spiritual, cultural and historical component to being two-spirit originating from Indigenous cultural beliefs and practices pre-contact and it is important to acknowledge that this differs from identifying as LGBTQ+ Indigenous.
}

supported the validity of information collected in our trials [73]. However, the validation did not include the primary variables included in the current study. Further, given that the participants were selected based on current mental disorder this may have further compromised some of their responses. Baseline interviews were conducted prior to randomization to a housing intervention, which may have introduced bias if participants believed that their responses might influence assignment. However, it is not clear what direction such bias might take. Gender was self-identified with the categories of male and female and did not allow for an examination of other sexual orientations. Indigenous ethnicity was also measured through self-report and categorized as "yes/no," although participants were asked if they identify specifically with First Nations, Inuit, Métis, or status and non-status. This study was not adequately powered to investigate differences between these identity groups. As a result of a long history of mistreatment within the healthcare system, many Indigenous people choose not to identify as Aboriginal in survey instruments for fear of discrimination. It is unknown whether similar concerns may have suppressed disclosure of Indigenous ethnicity in our study. We combined samples between sites with very differing proportions of Indigenous people (15 vs $70 \%$ ). These differences were expected based on prior knowledge of the Winnipeg and Vancouver contexts, but it is not clear whether there are meaningful differences between Indigenous participants in different sites. Further research is required to investigate and identify best practices for Indigenous people who are homeless and mentally ill, and their generalizability across settings. Housing First strategies have promise, particularly if they incorporate culturally-relevant services that account for trauma histories, gender, and structural violence. Our study was an exploratory investigation 
secondary to the main objective to examine housing stability post-randomization. Our multi-variable and univariate comparisons are preliminary and should be interpreted as hypothesis generating.

\section{Conclusions}

Housing policies and interventions for Indigenous Canadians must incorporate evidence of distinct needs associated with gender. Indigenous people experience homelessness in the context of historical and contemporary colonization. Violence and ongoing trauma have particularly forceful effects on the wellness of Indigenous women, their families, and communities. Yuan et al. (2015) described a research agenda for violence against American Indian and Alaska native women, calling for participatory research to develop culturally appropriate, strengths based interventions [74]. Similarly, Canadian researchers Browne et al. (2016) have described an approach to developing Equity Oriented Services, emphasizing culturally-safe care, trauma- and violenceinformed care, and contextually-tailored care, all operating in partnership with Indigenous people. Further research and Indigenous leadership are required to investigate how culturally safe, trauma informed care can be incorporated into existing housing policy and programming. The current study found that the repercussions of colonization were evident in distinct ways among Indigenous men and women who were living with significant psychological distress and homeless in Canada. Practices that are informed by these differences are essential to redressing the displacement of Indigenous women into homelessness, violence, and other forms of societal victimization.

\section{Abbreviations}

AOR: Adjusted Odds Ratio; BC: British Columbia; Cl: Confidence Interval; DTES: Downtown Eastside of Vancouver; ER: Emergency Room; EuroQol5D: Health Related Quality of Life Scale; HF: Housing First; HN: High Needs; IPV: Interpersonal violence;" LEC: Lived Experience Circle; LGBTQ2S: Lesbian, Gay, Bisexual, Trans, Queer, Two-Spirit; MCAS: Multnomah Community Ability Scale; MINI: Mini International Neuropsychiatric Interview: Maudsley Addiction Profile; PTSD: Post-Traumatic Stress Disorder; PWLE: Persons with lived experience; SRO: Single Room Occupancy Hotel; UOR: Unadjusted Odds Ratio

\section{Acknowledgements}

The authors thank the At Home/Chez Soi Project collaborative at both national and local levels; National project team: J. Barker, PhD (2008-2011) and C. Keller, National Project Leads; P. Goering, RN, PhD, Research Lead; approximately 40 investigators from across Canada and the US; 5 site coordinators; numerous service and housing providers; and persons with lived experience. Furthermore, we would like to thank the Indigenous participants in both Vancouver and Winnipeg for sharing their information, histories and stories for this project.

\section{Authors' contributions}

$\mathrm{BB}$ is the lead in the development of the manuscript. AM carried out the primary statistical analyses. MP, JD, JS, and JO contributed to the editing of the manuscript. JMS was the principal investigator, contributed to the research design and writing of the manuscript. All authors read and approved the final manuscript.

\section{Funding}

This work was supported by a grant to Simon Fraser University from Health Canada and the Mental Health Commission of Canada. Health Canada as the funder played no role in the study design; collection, management, analysis and interpretation of the data; writing the reports; or decisions to submit for publication. Some employees of the Mental Health Commission of Canada participated as research team members and played a role in all of these activities. However, ultimate authority for the study rests with the university investigators [36]. The views expressed herein solely represent the authors.

\section{Availability of data and materials}

Data is stored at St. Michael's Hospital in Toronto and is available to external investigators who sign a Data Sharing and Use Agreement that stipulates the responsibilities associated with transfer of datasets. Dr. Carol Adair at the University of Calgary is the data access coordinator. The corresponding author may be contacted for inquiries regarding data access.

\section{Ethics approval and consent to participate}

Office of Research Ethics, Simon Fraser University and the Health Research Ethics Board at the University of Manitoba. Participants provided written informed consent to participate in the study.

\section{Consent for publication}

"Not applicable".

\section{Competing interests}

The authors declare that they have no competing interests.

\section{Author details}

'Somers Research Group, Faculty of Health Sciences, Simon Fraser University, Burnaby, BC, Canada. ${ }^{2}$ Psychology and Community Health Sciences, University of Manitoba, Winnipeg, MB, Canada. ${ }^{3}$ Geography, University of Winnipeg Winnipeg, MB, Canada. ${ }^{4}$ Faculty of Health Sciences, Simon Fraser University Burnaby, BC, Canada.

Received: 8 October 2018 Accepted: 26 July 2019

Published online: 28 August 2019

\section{References}

1. Anderson JT, Collins D. Prevalence and Causes of Urban Homelessness Among Indigenous Peoples: A Three-Country Scoping Review. Housing Studies [Internet]. Routledge; 2014;29(7):959-76. Available from: http://www. tandfonline.com/doi/abs/10.1080/02673037.2014.923091

2. Patrick C. Aboriginal homelessness in Canada [Internet]. Toronto, ON: Canadian Homelessness Research Network Press; 2014 pp. 1-80. Available from: https://www.homelesshub.ca/sites/default/files/ AboriginalLiteratureReview.pdf

3. Gaetz S, Dej E, Redman M. The state of homelessness in Canada 2016 Toronto, ON: Canadian Observatory on Homelessness Press; 2016. p. 1-85.

4. Distasio J, Sylvestre G, Mulligan S. Home is where the heart is and right that is nowhere: an examination of hidden homelessness among aboriginal Peoples in prairie cities; 2005. p. 1-165.

5. Thomson M. Vancouver homeless count 2016 [internet]. Vancouver, BC: City of Vancouver; 2016 pp. 1-54. Available from: http://vancouver.ca/files/cov/ homeless-count-2016-report.pdf

6. Thurston W, Turner D, Bird C. Community-engaged scholarship: a path to new solutions for old problems in indigenous homelessness. In: Peters $\mathrm{E}_{\text {, }}$ Christensen J, editors. Indigenous homelessness: perspectives from Canada, Australia and New Zealand. Winnipeg, MB: University of Manitoba Press; 2016. p. 149-60

7. Halseth R. Aboriginal Women in Canada: gender, socio-economic determinants of health, and initiatives to close the wellness-gap. Prince George, BC: National Collaborating Centre for Aboriginal Health; 2013. p. $1-20$.

8. McGrath A, Stevenson W. Gender, race, and policy: aboriginal Women and the state in Canada and Australia. Gender Race Policy. 1996;(71):37-53.

9. Stratford A. Racialization of Poverty [Internet]. Vancouver, BC: Vancouver status of Women's racialization of poverty project; 2007 pp. 1-25. Available from: http://www.vsw.ca/Indigenous\%20Women_DEC2007FINAL.pdf.

10. Hunt S. Embodying self-determination: beyond the gender binary. In: Greenwood M, de leeuw S, Lindsay NM, Reading C, editors. Determinants of 
Indigenous Peoples Health in Canada. Toronto, Canada: Canadian Scholars Press Inc; 2015. p. 104-19.

11. Menzies $P$. Homeless aboriginal men: effects of intergenerational trauma. In: Hulchanski DJ, Campsie P, Chau S, Hwang SW, Paradis E, editors. Finding home policy options for addressing homelessness in Canada. Toronto: Cities Centre, University of Toronto; 2009. p. 1-25.

12. Allan B, Smylie J. First Peoples, second class treatment: The role of racism in the health and well-being of indigenous Peoples in Canada. Toronto: The Wellesley Institute. https://www.wellesleyinstitute.com/wp-content/ uploads/2015/02/Summary-First-Peoples-Second-Class-Treatment-Final.pdf.

13. Amnesty international. Violence against indigenous Women and girls in Canada [Internet]. Ottawa, ON: Amnesty International; 2014. p. 1-12. Available from: https://www.amnesty.ca/sites/amnesty/files/iwfa_ submission_amnesty_international_february_2014___final.pdf.

14. Bellamy S, Hardy C. Post-traumatic stress disorder in aboriginal people in Canada. Prince George, BC: National Collaborating Centre for Aboriginal Health; 2015. p. 1-28.

15. Hunt S. Colonial roots, contemporary risk factors: a cautionary exploration of the domestic trafficking of aboriginal Women and girls in British Columbia, Canada. Alliance News. 2010;33:27-31.

16. Lancet T. Canada's Inquiry into Violence Against Indigenous Women. Lancet. 2016;388(10046):732. https://www.thelancet.com/journals/lancet/ article/PIIS0140-6736(16)31413-1/fulltext.

17. Hotton Mahony T, Jacob J, Hobson H. Women and the criminal justice system. Statistics Canada; 2017 pp. 1-42.

18. Kirkby C, Women First MK. In: Nichols N, Doberstein C, editors. An analysis of trauma informed, Women-centered, harm reduction housing model for Women with complex substance use and mental health issues. Toronto, ON: Canadian Observatory on Homelessness; 2016. p. 1-18.

19. Whitzman C. Making the invisible visible: Canadian women, homelessness, and health outside the "big city.". In: Hulchanski DJ, Campsie P, Chau S, Hwang SW, Paradis E, editors. Finding home policy options for addressing homelessness in Canada. Toronto: Cities Centre, Unviersity of Toronto; 2010. p. 1-24.

20. Ghosh $\mathrm{H}$, Benoit $\mathrm{C}$, Bourgeault I. Health service needs for urban indigenous Women with co-occurring health concerns. Fourth World J. 2017;15(2):1-22.

21. Zlotnick C, Tam T, Bradley K. Long-term and chronic homelessness in homeless Women and Women with children. Soc Work Public Health. 2010 Aug 31;25(5):470-85

22. Browne AJ, Varcoe CM, Wong ST, Smye VL, Lavoie J, Littlejohn D, et al. Closing the health equity gap: evidence-based strategies for primary health care organizations. Int J Equity Health. 2012;11(1):59-16.

23. Ruttan L, LaBoucane-Benson P, Munro B. "A story I never heard before": aboriginal young Women, homelessness and Restorying connections. Pimatisiwin A J Aboriginal Indigen Commun Health. 2008;6(3):1-24.

24. Schiff R, Waegemakers Schiff J. Housing needs and preferences of relatively homeless aboriginal Women with addiction. Soc Development Issues. 2010; 32(3):65-76.

25. Walsh CA, MacDonald P, Rutherford GE, Moore K, Krieg B. Homelessness and incarceration among aboriginal Women: an integrative LiteratureReview. Pimatisiwin A J Aboriginal Indigen Commun Health. 2012; 9(2):363-86.

26. Christensen J. Indigenous Homelessness. In: Peters E, Christensen J, editors, Indigenous homelessness: perspectives from Canada, Australia and New Zealand. Winnipeg, MB: University of Manitoba Press; 2016. (Canadian Context).

27. John E. Indigenous resilience, connectedness and reunification - from root causes to root solutions. Victoria, BC; 2016. p. 1-220. Available from: http:// fns.bc.ca/wp-content/uploads/2017/01//Final-Report-of-Grand-Chief-Ed-Johnre-Indig-Child-Welfare-in-BC-November-2016.pdf

28. Duff $P$, Bingham B, Simo A, Jury D, Reading C, Shannon K. The 'stolen Generations' of mothers and daughters: child apprehension and enhanced HIV vulnerabilities for sex Workers of Aboriginal Ancestry. Braitstein P, editor. PLoS ONE. Public Libr Sci. 2014;9(6):e99664-6.

29. Crey E, Fournier S. Stolen From Our Embrace. Vancouver, BC: Douglas \& Mclntyre; 1997.

30. Whitzman C. Making the invisible visible: Canadian women, homelessness, and health outside the "big city.". In: Hulchanski DJ, Campsie P, Chau S, Hwang SW, Paradis E, editors. Finding home policy options for addressing homelessness in Canada. Toronto: Cities Centre, Unviersity of Toronto; 2012. p. 1-24.
31. Riley ED, Weiser SD, Sorensen JL, Dilworth S, Cohen J, Neilands TB. Housing patterns and correlates of homelessness differ by gender among individuals using San Francisco free food programs. J Urban Health. 2007 Jan 30;84(3):415-22.

32. Rich AR, Clark C. Gender differences in response to homelessness services Evaluation and Program Planning. 2005 Feb;28(1):69-81.

33. Clark C, Rich AR. Outcomes of homeless adults with mental illness in a housing program and in case management only, vol. 54; 2003. p. 1):1-6.

34. Whitzman C. At the intersection of invisibilities: Canadian women, homelessness and health outside the "big city.". Gend Place Cult. 2006 Aug 15;13(4):383-99.

35. Somers JM, Patterson ML, Moniruzzaman A, Currie LB, Rezansoff SN, Palepu A, et al. Vancouver at home: pragmatic randomized trials investigating housing First for homeless and mentally ill adults. Trials Trials. 2013;14:1):1-20.

36. Goering PN, Streiner DL, Adair CE, Aubry T, Barker J, Distasio J, et al. The at home/chez Soi trial protocol: a pragmatic, multi-site, randomised controlled trial of a housing First intervention for homeless individuals with mental illness in five Canadian cities. BMJ Open [Internet]. 2011;1(2):e000323-e000323. Available from: https:// bmjopen.bmj.com/content/1/2/e000323.

37. Bingham B, Moniruzzaman A, Patterson ML, Distasio J, Sareen J, ONeil $J$, et al. Indigenous and non-indigenous people experiencing homelessness and mental illness in two Canadian cities: a retrospective analysis and implications for culturally informed action. BMJ Open Br Med J Publ Group. 2019;9(4):e24748-10.

38. Distasio J, Sareen J, Isaak C. Winnipeg final report: at home/chez Soi project. Calgary, AB: Mental Health Commission of Canada; 2014.

39. Linden IA, Mar MY, Werker GR, Jang K, Krausz M. Research on a vulnerable neighborhood-the Vancouver downtown eastside from 2001 to 2011. J Urban Health Springer US. 2012;90(3):559-73.

40. Collins AB, Boyd J, Damon W, Czechaczek S, Krüsi A, Cooper H, et al. Surviving the housing crisis_social violence and the production of evictions among women who use drugs in Vancouver, Canada. Health Place Elsevier Ltd. 2018:51:174-81.

41. McNeil R, Shannon K, Shaver L, Kerr T, Small W. Negotiating place and gendered violence in Canada's largest open drug scene. Int J Drug Policy Elsevier BV. 2014;25(3):608-15.

42. Metro Vancouver. Metro Vancouver's Profile of First Nations with Interests in the Region 2018 [Internet]. Vancouver, BC; 2018 pp. 1-28. Available from: http://www. metrovancouver.org/services/irst-nation-relations/AboriginalPublications/ ProfileOfFirstNations.pdf

43. Métis Nation. Métis Nation: Who are the Métis [Internet]. Métis Nation. Ottawa, ON; 2018 [cited 2018 Jul 1]. Available from: http://www.metisnation. ca/index.php/who-are-the-metis

44. Patterson ML, Moniruzzaman A, Somers JM. Setting the stage for chronic health problems: cumulative childhood adversity among homeless adults with mental illness in Vancouver, British Columbia. BMC Public Health [Internet]. 2014;14(1):350-10 Available from: BMC Public Health.

45. Patterson ML. History of foster care among homeless adults with mental illness in Vancouver, British Columbia: a precursor to trajectories of risk. BMC Psychiatry. 2015;15(1):1-11.

46. Somers JM, Moniruzzaman A, Patterson ML, Currie LB, Rezansoff SN, Palepu $\mathrm{A}$, et al. A randomized trial examining housing First in congregate and scattered site formats. Puebla I, editor. PLoS ONE Public Library of Science. 2017;12(1):e0168745-14.

47. Corrigan PW, Salzer M, Ralph RO, Sangster Y, Keck L. Examining the factor structure of the recovery assessment scale. Schizophr Bull. 2004 Jul 21;30(4): 1035-41.

48. Corrigan PW, Giffort D, Rashid F, Leary M, Construct OIR a a P. Community Ment Health J. 1999;35(3):1-10.

49. Latimer EA, Lecomte T, Becker DR, Drake RE, Duclos I, Piat M, et al. Generalisability of the individual placement and support model of supported employment: results of a Canadian randomised controlled trial. Br J Psychiatry. 2006;189(01):65-73.

50. Dennis ML, Chan Y-F, Funk RR. Development and Validation of the GAIN Short Screener (GSS) for Internalizing, Externalizing and Substance Use Disorders and Crime/Niolence Problems Among Adolescents and Adults. Am J Addict. Wiley/Blackwell (10.1111); 2006;15(s1):80-91. 
51. Lamers LM, Bouwmans CAM, van Straten A, Donker MCH, Hakkaart L. Comparison of EQ-5D and SF-6D utilities in mental health patients. Health Econ. 2006;15(11):1229-36.

52. Uttaro T, Lehman A. Graded response modeling of the quality of life interview. Evaluation and Program Planning. 1999 Mar 30;22:41-52.

53. Pettersson A, Modin S, Wahlström R, af Winklerfelt Hammarberg S, Krakau I. The Mini-international neuropsychiatric interview is useful and well accepted as part of the clinical assessment for depression and anxiety in primary care: a mixed-methods study. BMC Fam Pract BioMed Central. 2018;19(1):52-14.

54. Barker S, Barron N, McFarland BH, Bigelow DA, Carnahan T. A community ability scale for chronically mentally ill consumers: part II. Applications. Community Ment Health J. 1994;30(5):459-72.

55. Rothman KJ. No adjustments are needed for multiple comparisons. Epidemiology. 1990 Jan;1(1):43-6.

56. Althouse AD. Adjust for multiple comparisons? It's not that simple. Ann Thorac Surg. 2016;101(5):1644-5.

57. Brennan S. Violent victimization of Aboriginal Women in the Canadian Provinces, 2009. Ottawa, ON: Statistics Canada; 2011. p. 1-21. Report No.: $85-002-X$

58. Brownridge DA. Understanding the Elevated Risk of Partner Violence Against Aboriginal Women: A Comparison of Two Nationally Representative Surveys of Canada. J Fam Viol. 2nd ed. Springer US; 2008;23(5):353-367.

59. Tolomiczenko G, Goering P. Gender differences in legal involvement among homeless shelter users. Int J Law Psychiatry. 2001 Dec;24(6):583-93.

60. Gwadz MV, Nish D, Leonard NR, Strauss SM. Gender differences in traumatic events and rates of post-traumatic stress disorder among homeless youth. J Adolesc. 2007 Feb;30(1):117-29.

61. King M, Smith A, Gracey M. Indigenous health part 2: the underlying causes of the health gap. The Lancet Elsevier Ltd. 2009;374(9683):76-85.

62. Nasir BF, Hides L, Kisely S, Ranmuthugala G, Nicholson GC, Black E, et al. The need for a culturally-tailored gatekeeper training intervention program in preventing suicide among indigenous peoples: a systematic review. BMC Psychiatry. 2016;16(1):404-8.

63. Ellsberg $\mathrm{M}$, Jansen HA, Heise L, Watts $\mathrm{CH}$, Garcia-Moreno C. Intimate partner violence and women"s physical and mental health in the WHO multi-country study on women"s health and domestic violence: an observational study. Lancet. 2008;371(9619):1165-72.

64. Eynan R, Langley J, Tolomiczenko G, Rhodes AE, Links P, Wasylenki D, et al. The association between homelessness and suicidal ideation and behaviors. Suicide Life Threat Behav. 2002;32(4):1-10.

65. Tolomiczenko G, Goering PN. The process and politics of communitybased research with people currently homeless. Psychiatr Rehabil J. 2000;24(1):1-6.

66. MacNeil MS. An epidemiologic study of aboriginal adolescent risk in Canada: the meaning of suicide. J Child Adolescent Psychiatr Nurs. 2008;21(1):3-12

67. Ansloos J. Rethinking Indigenosu suicide. International Journal of Indigenous Health. 2018;13(2):8-28.

68. Chandler MJ, Dunlop WL. In: Greenwood M, de leeuw S, Lindsay NM, Reading $C$, editors. Cultural wounds demand cultural medicines. Toronto, ON: Determinants of Indigenous Peoples Health in Canada; 2015 .

69. Thistle J. Indigenous definition of homelessness in Canada. Toronto, Ontario: Canadian Observatory on Homelessness Press; 2017.

70. Novac S, Darden J, Hulchanski DJ, Seguin A-M, Berneche F. Housing discrimination in Canada: the state of knowledge [Internet]. Ottawa, ON: Canada Mortgage and Housing Corporation; 2002. Available from: http://publications.gc.ca/site/eng/391021/publication.html.

71. Abramovich A, Shelton J. Where Am I to Go? Intersectional Approaches to Ending LGBTQ2S Youth Homelessness in Canada \& the U.S. Toronto: Canadian Observatory on Homelessness Press. 2017. http://publications.gc.ca/site/eng/391021/publication.html.

72. Abramovich A. In: Kidd S, Slesnick N, Frederick T, Karabanow J, Gaetz $S$, editors. Mental health \& addiction interventions for youth experiencing homelessness: practical strategies for front-line providers. Toronto, ON: Canadian Observatory on Homelessness Press; 2018.

73. Somers JM, Moniruzzaman A, Currie LB, Rezansoff SN, Russolillo A, Parpouchi M. Accuracy of reported service use in a cohort of people who are chronically homeless and seriously mentally ill. BMC Psychiatr BMC Psychiatr. 2016;16(41):1-7.

74. Yuan NP, Belcourt-Dittloff A, Schultz K, Packard G, Duran BM. Research agenda for violence against American Indian and Alaska native women: toward the development of strength-based and resilience interventions. Psychol Violence. 2015;5(4):367-73.

\section{Publisher's Note}

Springer Nature remains neutral with regard to jurisdictional claims in published maps and institutional affiliations.
Ready to submit your research? Choose BMC and benefit from:

- fast, convenient online submission

- thorough peer review by experienced researchers in your field

- rapid publication on acceptance

- support for research data, including large and complex data types

- gold Open Access which fosters wider collaboration and increased citations

- maximum visibility for your research: over $100 \mathrm{M}$ website views per year

At BMC, research is always in progress.

Learn more biomedcentral.com/submissions 